\title{
Natural science education concept for sustainable development
}

\author{
Lina Rybalko ${ }^{1, *}$, Oleg Topuzov², and Lyudmila Velychko ${ }^{2}$ \\ ${ }^{1}$ National University "Yuri Kondratyuk Poltava Polytechnic", 24 Pershotravnevyj Ave., Poltava, 36011, Ukraine \\ ${ }^{2}$ National Academy of Educational Sciences of Ukraine, 52-A Sichovykh Striltsiv Street, Kyiv, 04053, Ukraine
}

\begin{abstract}
The article is revealed essence and the concept of "ecological and evolutionary approach", conceptual ideas of ecological and evolutionary approach (the idea of evolution and the idea of ecocentrism) are disclosed. Author determined methodological principles of ecological and evolutionary approach to teaching. The concept of teaching natural sciences on the basis of ecological and evolutionary approach and didactic principles of implementation of ecological and evolutionary approach to the teaching of natural sciences (didactic conditions, principles and laws) are developed and scientifically substantiated which is visualized in a didactic model of teaching natural science on the basis of ecological and evolutionary approach. The technology of teaching biology based on ecological and evolutionary approach is developed. Results of pedagogical experiment proved the effectiveness of the technology of teaching biology on the basis of ecological and evolutionary approach and the conception and implementation of teaching principles of ecological and evolutionary approach to the teaching of natural sciences embodied in it.
\end{abstract}

\section{Introduction}

The global issues determining the future prospects include society, humanity and nature in their interrelation and interdependence. Today the fact that there is a real threat of environment balance upsetting as the result of unrestrained anthropogenic activities is indisputable. It is evidenced by numerous modern environmentalists' researches whose works prove environmental degradation in Ukraine: soil depletion, rivers and lakes pollution, ecosystems degradation, etc.

Current environmental situation requires an immediate resolution. That is why the search for effective environmental problem solving and, consequently, ways to harmonize the relations between society, human and nature becomes urgent and expedient. Currently Land (1992), Forest (1994) and Water (1995) Codes, a number of laws concerning the protection of the natural environment are effective in Ukraine, and a National Environmental Policy Strategy up to 2020 has been developed. However, it is necessary to find effective ways of the existing environmental problems elimination and new one's prevention.

The current stage of human interaction with nature is characterized by a significant aggravation of local, regional and global environmental problems (natural environment negative changes, populations gene pool disruption, natural resources depletion) leading to human life and health deterioration. These problems are of social character as they are caused by human activity, people's attitude towards nature in accordance with their social development. The idea that it is possible to stop the ecological crisis escalation only if they rethink their behavior culture and maintain the balance in nature should be established in the minds of people. We see the way to ecological culture, consciousness, thinking that have become a necessary condition for the harmonious and environmentally safe society development at the turn of the second and third millennia in quality science education.

\section{Purpose}

The purpose of the study is to explore the nature, content and conceptual ideas of an ecological-evolutionary approach to the natural sciences teaching for the sustainable development of society. In order to achieve this goal the main study objectives were defined: 1) to reveal the content and scope of the concept of "ecologicalevolutionary approach" on the basis of philosophical, ecological, pedagogical and natural-scientific literature review and collation; 2) to establish scientifically the ideas of evolution and ecocentrism as conceptual frameworks of sustainable development education; 3 ) to reveal the basics and to explain the meaning of ecologicalevolutionary world view; 4) to experimentally test the pupils' ecological-evolutionary worldview formation as a result of learning on the basis of ecological-evolutionary approach.

\section{Discussion}

The main goal of civilization development is to provide eco-evolution (joint, concerted, nature-aligned development) of humanity and biosphere [1]. In the $21 \mathrm{st}$

\footnotetext{
"Corresponding author: lina-rybalko@ukr.net
} 
century humanity has brought planetary civilization to crisis. The way to its overcoming is in the mastery of holistic thinking in accordance with the laws of nature and leading to ecological culture.

Above all, the intellectual potential should provide the society transition to safe sustainable development requiring qualitative transformation of people themselves who would obtain the capacity for a global worldview. The understanding of the relation between the development (evolution) of society and ecological problems, people's dependence on nature and its development and not vice versa should be established in the mind of modern human, filling us with the hope for global catastrophes prevention, the biosphere stability loss above all [2].

School, education, society should prepare a person able to live in a global space. That is why we believe that the crisis phenomena in society resulting from its negligence can be overcome through the formation of a person of a new type - the person of the future.

L. Rybalko defines the person of the future as educated, cultured, morally developed, able to undertake competent responsibility for new social progress directions, for the environment safe condition. The author wrote: "Actually as well as the whole world Ukraine is expecting a new era and simultaneously it is searching for a social, economic and scientific-technical survival platform, a new paradigm of a person's preparation for life that would provide not only an adaptive approach to reality but also harmonious development of reality itself in accordance with human life dimensions dictated by the ideals of the 21 st century" [3].

O. Topuzov emphasizes the role of education in the sustainable development of society in his works: "A mature personality, fully ready for life, able to act independently, make decisions, discern between good and bad, form relationships with different people and objects of nature in accordance with their own life positions, find the necessary information and use it successfully, building their mentality" [4].

Scientific education determines the level of society development, ways and means of environmental, economic, cultural problems solution and, ultimately, provides the citizens' life quality. In modern times humanity is facing three global problems: environmental, associated with the provision of biological balance of human and nature amidst the global environment pollution, techno-economic, associated with the planet's natural resources depletion, and socio-political. They may be solved only by the sufficiently theoretically trained experts possessing the fundamental planetary ecological worldview, familiar with the basics of modern natural science and ecology. The latter is provided by school science education and higher education establishments. At all times of human development natural and scientific knowledge formed the basis of the scientific worldview, because as a system of scientific knowledge about nature they revealed the universe structure and contributed to the knowledge of the fundamental laws of nature characterizing the holistic picture of the world of any era [3].
I. Ilyin [2], M. Romanenko [6] et al. tend to believe that the new educational system should be built on the principles of education for sustainable development forming the modern scientific worldview. We share their opinion that the primary task of education is to create a human consciousness contributing to the civilization survival. The only way of the transition to the society sustainable development is to form an "advanced consciousness", especially for the younger generation. Such consciousness will advance the existence - that's the essential factor for the effective and timely society transition to sustainable development leading to the harmonization of human relations with nature.

The conceptual ideas, their scientific validation and application in the content of science education in order to promote education for sustainable society development are required.

\section{Research results}

We regard the ecological-evolutionary approach in science education as a modern general scientific direction in the methodology of nature and its objects cognition as holistic systems with the explanation of their ecological relationships, evolution and their sustainable development prospects forecasting [4].

The ecological-evolutionary approach in the science education content is regarded as a social and pedagogical problem simultaneously. We associate its social content with the necessity for the human development harmonization, particularly the need to overcome global environmental problems, the transition from spontaneous human impact on nature to the conscious, purposeful interaction with it evolving deliberately. Such interaction is possible with a sufficient level of ecological competence including ecological culture, consciousness, thinking formed in each person. The pedagogical content of the problem is associated with the need for conceptual changes in the school science education content on the basis of society sustainable development implying the development of the pupils' holistic knowledge about nature, key natural science competence, value attitude to nature and appropriate behavior in the environment.

The content of the ecological-evolutionary approach is determined by the conceptual ideas of evolution or development and ecocentrism.

The application of the idea of evolution in the content of science education allows to reveal the nature evolution at equal levels of arrangement of matter, to establish the cause-and-effect relations and to provide internal dependence between the studied objects. The idea of ecocentrism as the worldview ideology of ecological attitude toward nature, environmental protection pursuant where to nature is regarded as a value independent of human preferences prioritized to the goals and needs of humanity provides the knower's comprehension of the connections between society and its natural environment, between the animate and inanimate nature objects as well as the ways of biosphere development and humanity survival [3]. 
The implementation of the idea of evolution together with the idea of ecocentrism in natural sciences teaching allows to show the pupils that the organic world has been evolving towards the natural systems structure complication corresponding to the adaptive capabilities and environment specificity, illustrates the related links between different natural objects, explains the nature development patterns, the interrelations between its systems advancing the nature integrity understanding, ecological thinking culture, value attitude towards nature and corresponding behavior in the environment formation in the young generation.

It was stated that the application of ecologicalevolutionary approach in the natural disciplines teaching makes it possible to realize that any organism including human independently forms its living environment, provides its stability creating optimal conditions for its existence; that the biosphere stability depends on its integrity and safe development.

The study revealed that the conceptual ideas of the ecological-evolutionary approach (evolution and ecocentrism) have a long generation history and appear relevant in the modern scientific dimension as their development in natural science led to the formation of a modern concept of global evolutionism as a system of notions of nature development process in all its various natural-historic forms: the evolution of the Solar System and the Universe, chemical evolution, the Earth evolution, biological and social evolution.

Thus, the conceptual ideas of ecological-evolutionary approach (the idea of evolution and the idea of ecocentrism) are dictated by the complex nature of the environmental problems that should be addressed to at the intersubject level. They are used in various scientific fields (philosophy, biology, geography, psychology and pedagogy) that proves their relevance, as environmental problems are of a global character and are rooted in the human life spheres covering worldview systems, social norms, ethnic, human relations, culture in general. Only a highly educated and highly spiritual society is able to implement the principle of co-evolution with nature that is a common, co-ordinated development. For the formation of such a society and its sustainable development achievement a new approach to the content of education (school and higher) characterized as ecological-evolutionary is required.

The essence of natural scientific cognition on the basis of ecological-evolutionary approach consists in: the nature evolution revelation; establishment and explanation of cause-and-effect relations of the objective reality systems functioning, their evolution on the basis of the laws of development and the laws of ecology; the desire to reveal the harmony of the universe, the harmony of relations between human and nature; affirmation of the interconnection of society and nature, human and their environment, understanding that both society and nature evolve together as a single process of co-evolution (coevolution is regarded as a form of joint development of two systems (social and natural) that does not lead to their destruction but provides ensures their harmonious existence)
The ecological-evolutionary worldview resulting in the ecological competence, ecological consciousness and ecological thinking formed in the person should become the nucleus of the new human ecological paradigm and ecological culture.

The ecological-evolutionary worldview (EEW) is explained as an evolving system of principles, views, knowledge, values, assessments, beliefs, practical guidelines determining a person's holistic comprehension of the unity of natural and social being, their co-evolution, governing the person's attitude towards the environmental problems and their solutions, form an active environmental viewpoint, encourage environmental activity and the biosphere development stability preservation. Such worldview type is peculiar to an environmentally educated person mindful of nature and involved in environmental management improvement. We consider such worldview type as a multidimensional integral component of the person's intellectual and spiritual culture providing their creative self-realization in environmental problems solution including responsibility for the state of the environment, the presence of ecological views and beliefs, experience in the natural environment studying and protecting.

The EEW formation contributes to the person's realization of the cause-and-effect relations between animate and inanimate nature, between nature and human, to the understanding that both nature and human evolve and these processes should occur in a coherent manner as co-evolutionary development. Human should build their relations with nature only on a scientific basis in order to predict the consequences of their activity and to regulate them without harming the nature, without disturbing its internal ecological balance and harmonious interrelations with society. It requires deep and comprehensive naturalscientific knowledge about the object of research, identification and realization of the patterns and tendencies of nature and society development constantly occurring under the influence of numerous naturalgeographical, socio-economic, socio-organizational factors, adequate application of scientific research methods. That is why we believe that the EEW may become the guide sign directing modern civilization to the harmonious relations with nature, the awareness of the unity and interdependence of humanity and nature.

The EEW presence in a person means the ability to solve the environmental problems of society and nature, to show the behavior that does not result in the biosphere destruction but contributes to its development, to understand the necessity for the interconnection of humanity and nature, to recognize the objective ecological and evolutionary relationships and their interdependencies.

The components of ecological-evolutionary worldview are intellectual, emotional-value and activity (Fig. 1).

The intellectual worldview component is represented by scientific and environmental knowledge playing the key role in the cognition of objective, historical and ecological realities. It is the knowledge of nature and human, understanding of the prospects of development of relations between society and nature; of the co-evolution 
of nature, human and society; understanding of the biosphere development stability dependence on human activity. All of this forms the young person's critical thinking corresponding to certain outlook, worldview and world perception, as shown in Fig. 1. Ecological knowledge as part of human cultural achievement support ecological ideal characterized by the mind covering the entire planet. Herewith the person becomes a consciously creative creature able to change the external world and their own nature with a high environmental culture. In modern times human relations with nature are far from ideal and require rethinking, as they often result in environmental problems. The high level of development of social consciousness, scientific ecological thinking, human ability to make decisions and act planetwide direct the ecological state of reality to the ideal. We believe that through environmentalization of the education content based on the idea of ecocentrism is required for that.

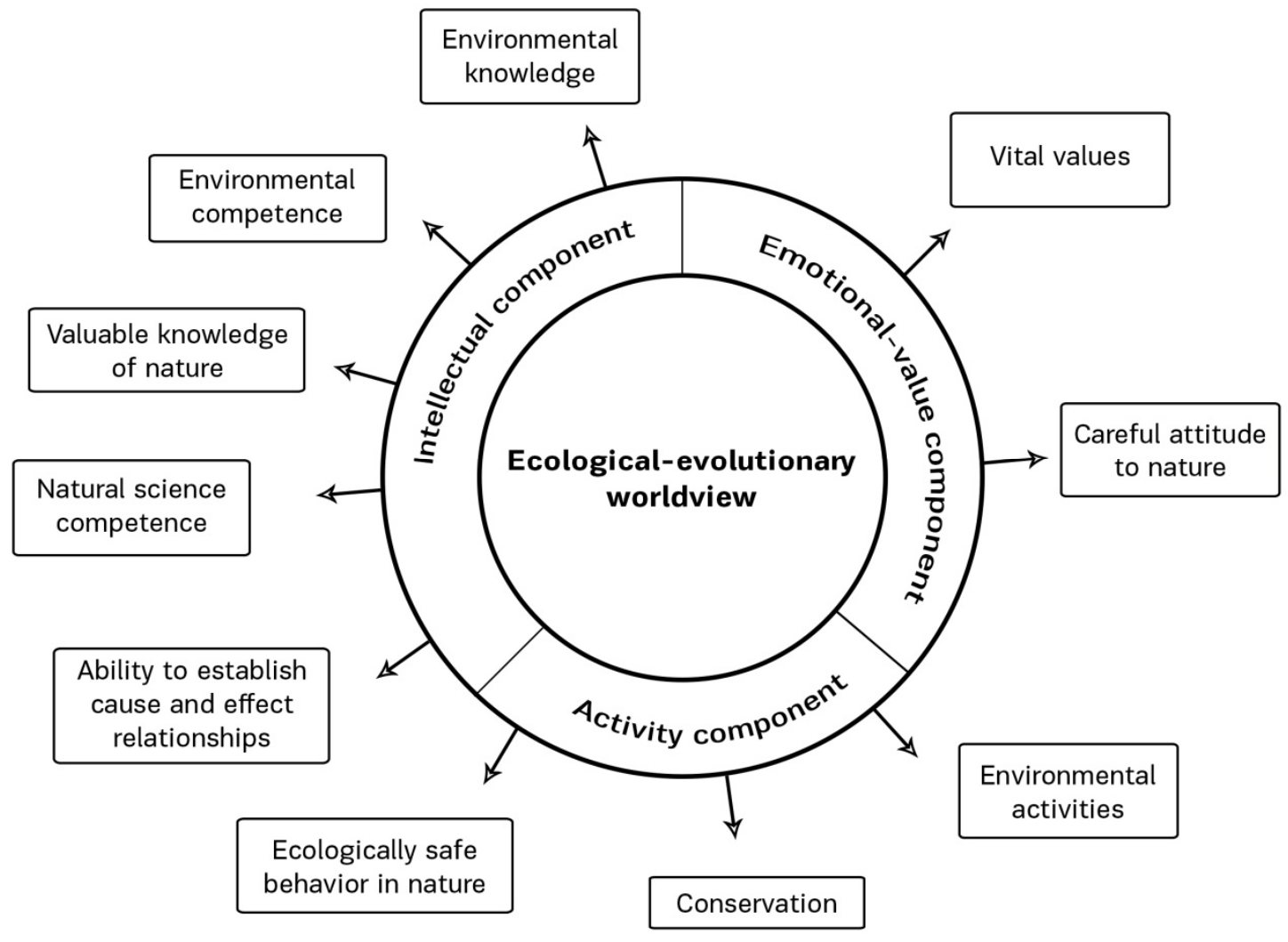

Fig. 1. The components of ecological-evolutionary worldview.

The emotional-value worldview component includes the person's vital values built on the basis of available knowledge, views and beliefs provided by the intellectual component. At that special attention is paid to the development of the person's sense of responsibility for the outside world, their environment and themselves, since responsibility plays the crucial role in natural and social environment rational transformation. The maturity of the EEW emotional-value component is manifested in the person's ability to perceive and understand the integrity of nature, to empathize with all living things, in the selfactualization need, in actual observation of the environmental laws, in resistance to the living environment integrity destruction, in motivation to study, in the desire and ability to keep a healthy lifestyle.

The activity EEW component provides for the person's inclusion in the sphere of interaction with nature, their activity in accordance with the level of knowledge and values available. The mature activity component results in the person's ability to act on the environmental basis with the purpose of preventing damage to the environment and nature. At that we consider activity as a form of active and simultaneously value-based attitude to the world, nature - the way of a human behavior in the biosphere.

In the context of our study we understand by the environmental activities not only educational activities aimed at the knowledge and skills system mastering, the formation of their environmental and scientific competencies together with the subject competencies system, but also the development of positive social and cultural motives of ecologically sound ethical behavior, deliberate activity promoting harmonization and optimization of relations between human and nature, developing ecological and cognitive interests. During ecological activity a person does not only adapt to the natural environment, but also adapts nature to themself, transforms it according to their needs. As a result, the person creates a socio-natural environment where in the course of environmental activities they change natural interrelations into social and cultural ones. At that the person is simultaneously the subject and the object of the environmental activity, the values whereof are their environmental needs.

Environmental activity as the activity EEW component is determined by the following imperatives: an 
environmentally sound labor management aimed at relations harmonization in the "human - society - nature" system; activation of environmental, resource-conserving activities; cultural environmental activities.

The EEW presence in person and its result environmental consciousness - form a new type of person whom we call an ecoperson.

An ecoperson is a type of person coordinating all their life activity with the laws of the biosphere evolution into noosphere, realizing the objectivity and irreversibility of this process; whose environmental and spiritual needs prevail over the material ones [4].

Modern society should form an ecoperson characterized by ecological education and consciousness implying an attitude towards the world as towards themselves, avoiding passive existence for active participation in the transformation of the biosphere into its sphere of reason - the noosphere. Since the modern environmental problems are not large and small Chornobyls, but deliberate consciousness destruction, humanity should move to a qualitatively new living standard - ecological consciousness, which will become the key to its survival.

Opposed to the ecoperson is the type of "homo civition". That is according to S. An [5] who characterizes the homo civition as a person who has lost their inner spirituality, often indifferent, apathetic, aggressive and angry.

"Homo civition, - S. An wrote, - is a person unpredictable in social activity, capable of unmotivated destructive (disruptive) actions, with destructive actions mindset only" [5]. Homo civition's consciousness contains elements of chaos, instability, randomness and disorganization, and the actions of this type of person is characterized by a significant weakening of leadership skills, increasing behavior deviations and so on.

We believe that humanity has only one way to the future - the formation of worldview, culture and mentality relevant to the modern era through the establishment and implementation of the idea of ecocentrism. The ecological and evolutionary worldview should become this worldview.

The implementation of ecological-evolutionary approach ideas in the content of scientific education is performed through an innovative technology of natural sciences (biology, geography, chemistry and physics) teaching.

The purpose of the pedagogical experiment was to organize, conduct and analyze the results of the implementation of natural sciences teaching technology based on the ecological-evolutionary approach principles and to check the ecological-evolutionary worldview formation in the $9^{\text {th }}$ grade pupils of general educational institutions.

In order to objectively evaluate the academic performance in biology of the pupils who have studied under the experiment (according to the innovative teaching technology based on the principles of ecocentrism idea implementation) a criteria system, their rates and levels of pupils' performance have been developed. Performance is understood to be the rate of pupils' mastery of empirical and theoretical knowledge (scientific concepts, facts, laws, theories, patterns), as well as of skills.

The following criteria for the pupils' academic performance evaluation in natural science subjects on the basis of ecological-evolutionary approach were determined: cognitive, activity-creative, personalsignificant, or reflective, motivational-behavioral. According to the stated criteria four integrated levels of pupils' performance were separated: elementary, intermediate, sufficient, high.

For the purpose of revealing the ecologicalevolutionary worldview formation in the mind of the 9th grade pupils and obtaining the qualitative and quantitative indicators of this process effectiveness the formative stage of pedagogical experiment was conducted.

The results of the pedagogical experiment suggested that the implementation of biology teaching technology on the basis of ecological-evolutionary approach to the 9th grade pupils (identified as the experimental in the study) contributed to a significant increase in the ecological and evolutionary worldview formation at high and sufficient levels according to all the criteria (cognitive, activity-creative, personal-significant and motivational-behavioral) and decrease in the number of pupils with low and intermediate levels which proves the effectiveness of the ecological-evolutionary approach implementation in the natural subjects teaching (Fig. 2).

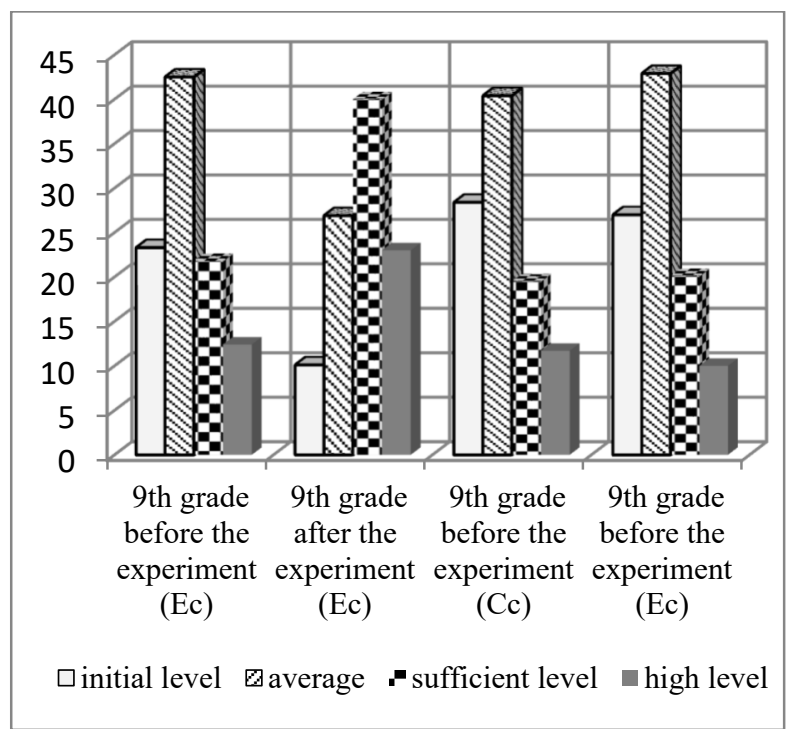

Fig. 2. The dynamics pattern of EEW formation levels of the 9th grade pupils in the experimental $(\mathrm{Ec})$ and control $(\mathrm{Cc})$ groups by the personal-significant criterion before and after the experiment.

The effectiveness of environmental studies subjects/disciplines teaching technology based on ecological-evolutionary approach was estimated during a pedagogical experiment in general comprehensive schools conducted on biology classes.

During the pedagogical experiment the subject student groups of 9th grade (Exp) pupils teaching was conducted following the education technology based on ecologicalevolutionary approach, based upon using original biology teaching methods with the ecological-evolutionary approach and an educational methodological provision 
system (biology textbooks, accordant guides for pupils and a methodological guide for teachers). In the control groups of $9^{\text {th }}$ grade $(\mathrm{Cc})$ the pupils studied according the classic education system following biology textbooks and guides that were based on ecological-evolutionary approach.

The achieved pedagogical experiment data analysis proves that students being taught biology on the basis of ecologic-evolutionary approach facilitated a major decrease in their quantity, with the lower ( from $19,4 \%$ to $4,9 \%$ according to the cognitive criteria, from $18,2 \%$ to $6,6 \%$ according to the activity and creativity criteria, from $16,2 \%$ to $7,4 \%$ according to personal importance criteria and from $17,7 \%$ to $6,4 \%$ according to motivation and creativity criteria) and middle (from $53,8 \%$ to $17,4 \%$ according to the cognitive criteria, from $45,9 \%$ to $19,8 \%$ according to the activity and creativity criteria, from $43,4 \%$ to 22,3 according to personal importance criteria and from $17,8 \%$ to $6,2 \%$ according to motivation and creativity criteria) levels of education, at the same time the number of students increase on satisfactory (from 24,0\% to $49,7 \%$ according to the cognitive criteria, from $23,7 \%$ to $47,2 \%$ according to the activity and creativity criteria, from $25,8 \%$ to $44,9 \%$ according to personal importance criteria and from $26,0 \%$ to $40,7 \%$ according to motivation and creativity criteria) and on higher (from $16,0 \%$ to $25,9 \%$ according to the cognitive criteria, from $12,1 \%$ to $26,6 \%$ according to the activity and creativity criteria, from $14,5 \%$ to $25,5 \%$ according to personal importance criteria and from $15,8 \%$ to $33,2 \%$ according to motivation and creativity criteria) levels (the data compared was gathered before and after the experiment). The changes in education level among the students in control groups are hardly noticeable.

Quantitative and qualitative analysis of the pedagogical experiment results proves that the teaching technology based on ecological-evolutionary approach is effective along with the concepts and didactic principles represented within it, which confirms the research original hypothesis. The research has proven that the ecologicalevolutionary approach application in teaching 9th graders biology substantially influences the quality of the pupil's knowledge: the formation of complex ideas about wildlife, biological knowledge capacity, ecological competence and ecological-evolutionary ideology.

\section{Conclusions}

Comparing the levels of ecological-evolutionary worldview formation of the 9th grade pupils in control and experimental classes who were taught according to ecological-evolutionary approach natural sciences teaching technology we found out that all the criteria at sufficient and high performance levels are much higher for the pupils of experimental classes than for the pupils of control classes. The difference in the number of $9^{\text {th }}$ grade pupils of control and experimental classes with elementary and intermediate performance levels according to the same criteria was revealed.

The results of the pedagogical experiment suggested that the implementation of biology teaching technology on the basis of ecological-evolutionary approach contributed to a significant increase in the ecological and evolutionary worldview formation at high and sufficient levels according to all the criteria (cognitive, activitycreative, personal-significant and motivationalbehavioral) and decrease in the number of pupils with low and intermediate levels which proves the effectiveness of the ecological-evolutionary approach technology in the natural subjects teaching.

\section{References}

1. N. Moiseyev, A. Ursul, F. Demidov, Ustoychivoye sotsioprirodnoye razvitiye (Sustainable socio-natural development). (Nauka, Moscow, 2016)

2. I. Il'in, Evolyutsionnyy podkhod k global'nym issledovaniyam i obrazovaniyu: teoretikometodologicheskiye problemy. Vek globalizatsii 1, 3-17 (2010)

3. L. Rybalko, Navchannya pryrodnychykh predmetiv na zasadakh ekoloho-evolyutsiynoho pidkhodu $v$ zahal'noosvitnikh navchal'nykh zakladakh: teoriya $i$ praktyka (Teaching natural disciplines of the principles of ecological evolutionary approach in general educational institutions theory and practice). (FO-P Myron I. A., Poltava, 2014)

4. O. Topuzov, Yakist' vitchyznyanoyi osvity - shlyakh do yevropeys'kykh standartiv. Humanitarnyy visnyk PoltNTU 1, 12-20 (2017)

5. S. An, Khomo tsvyshens yly chelovek hranytsy (Homo Tsvishens or the man of the temple). (Barnaul, 2011)

6. M. Romanenko, Osvitnya paradyhma: henezys idey ta system (Promin, Dnipropetrovsk, 2000) 